\title{
A comparison of white and black targets under conditions of masking by a patterned stimulus
}

\author{
DEAN G. PURCELL \\ Oakland University, Rochester, Michigan 48063 \\ and \\ ALAN L. STEWART \\ New York University, New York, New York 10003
}

\begin{abstract}
When the onset of a target field was followed in time by the onset of a patterned mask, white letters on a dark field were more accurately reported than black letters located on a white field. Presenting the letters to one side of the point of fixation caused observer performance to deteriorate, but white letters continued to be reported more accurately than black letters. For each constant interval measured from target onset to mask onset, letter recognition was facilitated by introducing a dark interval between target offset and mask onset.
\end{abstract}

When a visually presented target is followed closely in time by a spatially overlapping black and white patterned mask, recognition of the target may suffer. This decrement in recognition produced by a stimulus which follows the target in time is referred to as visual backward masking. According to some explanations of backward masking, the second stimulus, a masking stimulus, serves to stop the processing of the target stimulus and thus limits the availability of information from the target array. If one assumes that the mask stops information processing, a direct estimate of how long the information from a brief stimulus flash is available to an observer may be given by the size of that interval between target onset and mask onset at which masking effects begin reliably to occur.

In support of this notion, it has been demonstrated that under some conditions, the interval from target onset to mask onset, referred to as negative $S O A$ in this paper, predicts the amount of information extracted from the target stimulus (Haber \& Nathanson, 1969). Moreover, as long as SOA is held constant, introducing unfilled intervals of time between target of fset and mask onset-by such means, for example, as shortening the duration of the target-does not appear to affect target recognition. On the basis of a number of experiments yielding data similar to that of Haber and Nathanson, it has been concluded that it is the onset of the mask which interrupts the processing of any preceding information. To be confident that, in principle, at least, the onset of the mask does serve to stop information processing, however, the interaction of the target stimulus with the masking stimulus must be similar

Requests for reprints should be sent to Dean G. Purcell, Department of Psychology, Oakland University, Rochester, Michigan 48063. Research was partially supported by a grant from the Social and Rehabilitation Service to the second author. under a broad range of masking conditions. Yet the apparently simple relationship between SOA and target recognition, in which SOA almost completely predicts the level of observer performance, has not been studied carefully under conditions of dark adaptation, and, therefore, is still to be substantiated.

Experiments dealing specifically with the problem of visual backward masking suggest that the masking paradigm used in information processing studies may be more complex than is sometimes assumed. When a black disc is followed by a black ring mask, and SOA is held constant, increasing the duration of the target reduces target detectability (Purcell \& Stewart, 1969). Moreover, under backward masking by a flash of light, brightness judgments of black targets are less reliable than similar judgments of white targets (Stewart, Purcell, \& Dember, 1968). If the ability to recognize letter targets followed by a patterned mask also improves when white targets are substituted for black, then the idea that SOA predicts target recognition may be of limited use and certainly may no longer be regarded as a rule grounded upon an adequate theory of visual masking.

Additional issues relate such a comparison of black and white target letters to the luminance-summation, contrast-reduction hypothesis of visual masking. According to this viewpoint, masking results when target and mask are integrated so as to form a single percept (Eriksen, 1966; Thompson, 1966). When target and mask both contain high-contrast outlines, for example, the contours are defined by changes in the spatial distribution of the light upon the retina. By itself, the temporal integration of these points of illumination would result in a composite percept of the target and mask contours. Those dark portions of the target and mask which were superimposed upon each other would 


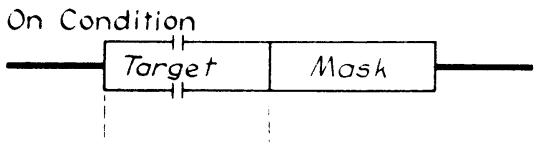

Short-Off Condition

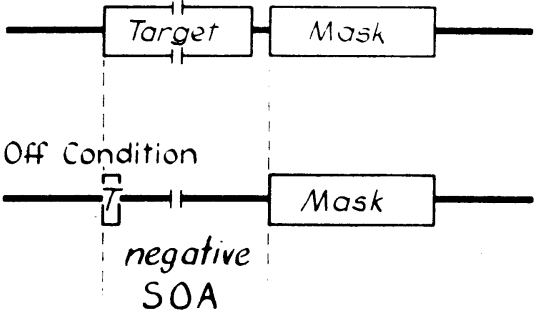

Time $\longrightarrow$

Figure 1. Timing diagram for the on, short-off, and off conditions.

remain dark, while the dark plus light parts of the target and mask would suffer the equivalent of contrast reduction (Thompson, 1966). As a result, the appearance of the target figure would be changed critically.

The same theoretical position holds that, with or without contrast reduction, the summing of the target contours with the contours of the mask would also serve to embed the target within a more complex field, obscuring the target's outline. Just as a figure hidden within a jumble of lines is difficult to see at first glance, such an embedded target is more difficult to locate or identify during a brief inspection period, such as that afforded by a tachistoscopic exposure (Eriksen \& Collins, 1965; Kinsbourne \& Warrington, 1962a, b). Both the contrast-reduction hypothesis as well as the idea that, in masking, the target becomes embedded within an obscuring field would predict that white letters and black letters should be equally difficult to identify under otherwise identical masking conditions. Therefore, if white letters are more readily identified than black letters, luminance summation must play a role less prominent in backward masking than has been assigned to it by many theorists.

\section{METHOD}

Three well-trained observers made forced-choice decisions as to which of two alphabetic letters had been presented on any one trial. The target stimulus consisted of a capital letter $D$ or $O$. The target letters were black on a white background, or white on a black background, thus giving two configurations of figure and background. In both conditions of figure and background, the letters subtended about .48 by $.40 \mathrm{deg}$ of arc. The strip width of the letters was $.08 \mathrm{deg}$. The white portion of each target field was constant at $65 \mathrm{~cd} / \mathrm{m}^{2}$. At this level of illumination, the black portion of the field was $3.8 \mathrm{~cd} / \mathrm{m}^{2}$

The target letters were exposed individually at the center of a dark fixation field defined by four red points of light arranged in a diamond-shaped pattern. The points were on an imaginary circle with its radius of $1.67 \mathrm{deg}$ measured from the site at which the target letters were presented. There were two fixation conditions-the observer looked either at the center of the diamond pattern or at the point of light $1.67 \mathrm{deg}$ left of center.

The patterned mask was composed of overlapping rows and columns of the black capital letters $N$ and $O$ on a white background. The size of the individual letters was equal to that of the target letters. The mask pattern subtended 2.55 by $3 \mathrm{deg}$, while the overall white background of both mask and target was $3 \mathrm{deg}$ square. The white portions of the mask, like those of the targets, were constant at $65 \mathrm{~cd} / \mathrm{m}^{2}$. The exposure duration of the mask was constant at $100 \mathrm{msec}$.

Four negative SOA intervals were used-30, 40, 50, and $60 \mathrm{msec}$. Three conditions of target presentation were investigated. In the on condition, the target was exposed for the duration of the given SOA; in the short-off condition, the target was exposed for all but the last $10 \mathrm{msec}$ of the given SOA; and in the off condition, the target was exposed for only $10 \mathrm{msec}$, regardless of the SOA value (see Figure 1).

Fifty trials were run under each condition in random blocks of 25 trials each, with the constraint that each 1-h experimental session alternated between using white or black letters as targets. The intertrial interval was $10 \mathrm{sec}$. All observations were binocular. Observers initiated each trial at a ready signal from the experimenter. Target configuration, point of fixation, SOA, and mode of presentation were the independent variables in a repeated measures analy sis of variance.

\section{RESULTS}

\section{Statistical Analysis}

The mean percent correct target report is displayed in Figure 2. The main effect of target configuration was statistically significant $[F(1,2)=196.35, \quad \mathrm{p}<.01]$. Target presentation was also statistically significant $[F(2,4)=458.71, p<.001]$, as well as stimulus onset (SOA) $[\mathrm{F}(3,6)=28.51, \mathrm{p}<.005]$. The analysis also produced a number of statistically significant two-way interactions: the interaction of target presentation with SOA $[F(6,12)=3.88, p<.05]$; target presentation by target configuration $[\mathrm{F}(2,4)=43.49, \mathrm{p}<.005]$; target

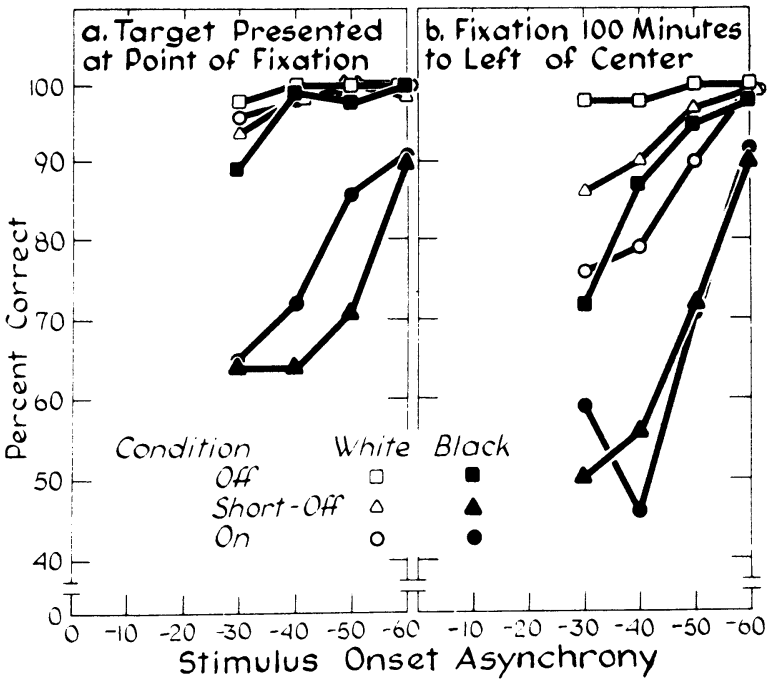

Figure 2. Percent correct report for black letters on a white background compared with white letters on a black background. (Four values of negative SOA are plotted for each condition.) 
configuration by SOA $[\mathrm{F}(3,6)=9.08, \mathrm{p}<.025]$; point of fixation by $\operatorname{SOA}[F(3,6)=9.85, \mathrm{p}<.01]$.

\section{Control Experiments}

The results of the present experiment indicate that the recognition of a white letter is less affected by a patterned mask than is recognition of a black letter. As they are reported above, however, the results cannot be considered conclusive. Because the masking stimulus was a pattern of black figures on a white background, it more closely approximated the stimulus configuration of the black letters than that of the white and might, therefore, have been an inappropriate mask for white letters. Two additional experiments, however, indicated that this similarity between target and mask features was not an important factor. These control experiments followed the procedure used in the main experiment, with the exception that only center fixation was employed. In both control experiments, the effectiveness of the black on white masking stimulus was compared with the masking effect of the reverse pattern of white letters on a dark background. Targets were black letters in one control experiment and white letters in the other. There were no reliable differences in effectiveness of the two mask patterns in either control experiment.

\section{DISCUSSION}

The finding that the low energy off condition produced the best target report resembles the results of a previous study (Purcell \& Stewart, 1974). This inverse relationship between target energy and target detection, in which stimuli of higher energy are more difficult to identify correctly than stimuli of lower energy, has also been found with disc targets and annular masking stimuli (Purcell \& Stewart, 1969; Purcell, Stewart, \& Dember, 1969) and with a bar target flanked by bar-shaped masking figures (Cox \& Dember, 1971).

The present experiment additionally substantiates previous findings that white disc targets were harder to mask than black disc targets. This relationship has been found for masking by a flash of light (Stewart, Purcell, \& Dember, 1968) and for metacontrast (Cox \& Dember, 1970). In metacontrast experiments, then, just as with other masking experiments, increasing the energy of the target can serve to interfere with target report under some conditions.

The similarity of these findings to the data presented herein suggests that the substitution of white for black targets may have the same effect as decreasing the energy of the target pulse. Stated differently, the effect of substituting white for black targets may be similar to that of changing target energy through manipulation of the target field luminance or duration. At the very least, these results also suggest that we reexamine many current explanations of why a masking stimulus interferes with the perception of a target. Neither luminance summation nor an interruption hypothesis gives a satisfactory explanation of the data presented in this paper.

\section{REFERENCES}

Cox, S. I., \& Dember, W. N. Backward masking of visual targets with internal contours. Psychonomic Science, 1970, 19, 255-256.

Cox, S. I., \& Dember, W. N. Effects of target-field luminance, interstimulus interval, and target-mask separation on extent of visual backward masking. Psychonomic Science, 1971, 22, 79-80.

Eriksen, C. W. Temporal luminance summation effects in backward and forward masking. Perception \& Psychophysics, 1966, 1, 87-92.

Eriksen, C. W., \& Collins, J. F. Reinterpretation of one form of backward and forward masking in visual perception. Journal of Experimental Psy chology, 1965, 70, 26-35.

Haber, R. N., \& Nathanson, L. S. Processing of sequentially presented letters. Perception \& Psychophysics, 1969, 5, 359-361.

Kinsbourne, M., \& Warrington, E. K. The effect of an aftercoming random pattern on the perception of brief visual stimuli. Quarterly Journal of Experimental Psychology, 1962a, 14, 223-234.

Kinsbourne, M., \& Warrington, E. K. Further studies on the masking of brief visual stimuli by a random pattern. Quarterly Journal of Experimental Psy chology, 1962b, 14, 235-245.

Purcell, D. G., \& Stewart, A. L. Facilitation of visual backward masking by increasing target duration: A methodological extension. Psy chonomic Science, 1969, 17, 360-361.

Purcell, D. G., \& Stewart, A. L. Backward masking by pattern mask: Effect of adaptation and target energy. Bulletin of the Psychonomic Society, 1974, 3, 137-138.

Purcell, D. G., Stewart, A. L., \& Dember, W. N. Backward masking: Facilitation through target-field luminance and duration. Psychonomic Science, 1969, 15, 87-88.

Stewart, A. L., Purcell, D. G., \& Dember, W. N. Masking and recovery of target brightness. Proceedings of the American Psychological A ssociation, 1968, 3, 109-110.

Thompson, J. H. What happens to the stimulus in backward masking. Journal of Experimental Psychology, 1966, 71, 580-586.

(Received for publication March 10, 1975.) 